\title{
A China Healthy Diet Index-based evaluation of dietary quality among pregnant women in coastal areas across trimesters and residential areas
}

\author{
Zhengyuan Wang \\ shanghai cdc \\ Jiaying Shen \\ shanghai municipal CDC \\ Yiwen Wu \\ Shanghai CDC \\ Xueying Cui \\ Shanghai CDC \\ Qi Song \\ Shanghai CDC \\ Zehuan Shi \\ Shanghai CDC \\ Wei Jin \\ Shanghai CDC \\ Changyi Guo \\ Shanghai CDC \\ Chunfeng Wu \\ Shanghai CDC \\ Jiajie Zang ( $\square$ zangjiajie@scdc.sh.cn ) \\ Shanghai CDC
}

\section{Research}

Keywords: pregnant women, China Healthy Diet Index, diet quality, trimester, residential area

Posted Date: November 2nd, 2020

DOl: https://doi.org/10.21203/rs.3.rs-95539/v1

License: (c) (7) This work is licensed under a Creative Commons Attribution 4.0 International License. Read Full License 


\section{Abstract}

Background: Good dietary quality among pregnant women is critical for maternal and fetal health. Comprehensive assessments of large representative samples are lacking.

Methods: Pregnant women were enrolled using a multistage, stratified, random-sampling method in Shanghai. We used a personal food frequency questionnaire and a household condiment weighing method for dietary assessments. Participants' scores on the China Healthy Diet Index (CHDI) were analyzed to evaluate diet quality.

Results: Significant differences in the median daily intake of almost all food types were found across all trimesters, and all food types were found across all residential areas (urban, suburban and rural). Significant differences were found in the median total CHDI scores across trimesters, and on all CHID components, except whole grains, dry beans and tubers, across all residential areas; $13.7 \%$ of participants scored below 60 points, indicating "poor" dietary quality. Significant differences in CHDI scores were found across trimesters and residential areas. Participants in early and middle pregnancy had lower scores than those in late pregnancy. Women in urban areas had higher scores than those in suburban and rural areas.

Conclusions: Pregnant women living in coastal areas of China suffer from an unbalanced diet of average quality. Pregnant women in the early and middle stages of pregnancy had worse scores than those in the late stage, while suburban and rural women had worse scores than urban women.

\section{Introduction}

Nutrition during pregnancy is a key determinant of pregnancy success and maternal and fetal health [1, 2]. Increased caloric and macronutrient intake in the 2nd and 3rd trimesters and micronutrients (e.g., iron and folate) throughout the gestational period are necessary for a healthy pregnancy. There is mounting evidence that a deficient or excessive intake of one or more macro- and micronutrients is common among pregnant populations through diets [3, 4]; under- and over-nutrition are thought to be involved in diseases, such as obesity, gestational diabetes mellitus, cardiovascular mortality and infant abortion. Thus, it is essential to monitor the dietary intake of pregnant populations to determine the degree to which they meet nutritional requirements in order to update public health messages and tailor recommendations.

Contrary to popular single-food and -nutrient studies, the Diet Quality Index has been used since 1999 [5], and has received increased attention as a tool for evaluating overall diet quality and for categorizing individuals based on their eating behavior, as dietary components are not consumed in isolation, but interact with one another [6]. The Healthy Eating Index (HEI), Diet Quality Index (DQI), Healthy Diet Indicator (HDI) and Mediterranean Diet Score (MDS) are the four original diet-quality scales that were based on dietary recommendations and validated internationally. However, these indexmay not be applicable to China because of its distinct dietary habits. The previous Chinese Diet Balance Index (DBI) and the revised instrument (DBI_16) were developed successively in China. The 2017 Chinese Healthy Diet Index (CHDI) is the latest comprehensive evaluation approach [7]. It is based on the 2016 Chinese Dietary Guidelines which captures variation in the components of dietary patterns, sensitively reflects under-and over nutrition and has proved useful in surveilling national nutrition transitions and epidemiological trends $[7,8]$.

Historically, numerous studies have examined the importance of dietary patterns and their long-term effects on health among various populations. A crosssectional study found that higher scores for "vegetables-fruits" and "snacks-drinks-milk products" patterns were associated with a reduced risk of cognitive impairment in older Chinese women [9]. Children who are breastfed are more likely to have healthier dietary patterns and those who eat more fruits and vegetables in late infancy are more likely to continue their eating habits at age 6 [10]. However, few investigations have focused on maternal dietary intake, and there is a lack of well-designed, population-representative studies. Furthermore, as an international coastal metropolis, Shanghai has its own regional and diet characteristics. The people have undergone noticeable changes in their diets and eating behaviors in the past decades, which probably have affected their food intake and health outcomes. Yet, with the rapid development of the economy and the food processing industry, diet quality among pregnant women in China has not been adequately assessed, and the associations of trimester and residential areas with diet quality need to be further investigated.

Pregnant women living in Shanghai were selected as the study's target population to address this gap in the literature and propose up-to-date suggestions. The primary objective of our study was to examine the food quality of pregnant woman along the coastal area across trimesters and residential areas using the CHDI.

\section{Materials And Methods Study Sample}

We collected data from participants in the lodine Status in Pregnancy and Offspring Health Cohort (ISPOHC) study, which was conducted in April-October 2017. The formula for calculating stratified random sampling sample size which was $n=z 2 * S 2 * d e f f / d 2$ was used to calculate the sample size required for analysis. At least 4269 pregnant women without illnesses that could interfere with the research process were needed for the survey. Women with missing foodconsumption data, and those whose energy intake was below $800 \mathrm{kcal} / \mathrm{d}$ or above $5000 \mathrm{kcal} / \mathrm{d}$ were excluded from the study after a discussion with experts, leaving 4574 eligible participants for the survey. A multistage, stratified random sampling method was used to obtain a representative sample. The metropolis consisted of urban, suburban and rural areas and they were categorized based on the ratio of the non-agricultural registered population in the sub-districts to those in town. The sample size in each administrative district was evenly determined in accordance with the sample size and the number of pregnant women in each administrative district in 2016. Each district was divided into five sections, a street was randomly selected from each section and an equal number of pregnant women were selected from each section. Participants in the different stages of pregnancy were evenly distributed. 
The Ethics Committee of the Shanghai Center for Disease Control and Prevention approved the survey. All of the surveys were conducted after written consent from the respondents was obtained.

\section{Data Collection}

Eligible participants were interviewed face-to-face to collect data on their demographics, pregnancy history, dietary habits, physical activity and related information. Dietary assessments were conducted using a personal food-frequency questionnaire and a household condiment weighing method to measure cooking oil, salt and sugar.

A validated and reliable food frequency questionnaire (FFQ) [11] was used to measure the frequency and amount of foods consumed by participants over the past three months. The average food recordings were calculated according to the requirements for each food (e.g., raw weight, edible weight, dry weight and fresh weight) and the conversion rate. Similar foods were counted together. Food and nutrient intake was estimated using food composition tables published for use in China [12]. Oil, salt and sugar data were obtained by dividing weight changes in the condiment inventory over one week by the number of people who consumed the household condiments together at each meal.

All data were reviewed by the local district Centers for Disease Control and Prevention (CDC) project team, and at least $5 \%$ of the data was reviewed by the Shanghai CDC project team.

\section{Assessment of Diet Quality}

The China Healthy Diet Index was used to evaluate overall patterns of dietary intake of the Chinese population, and it corresponds to the Chinese Dietary Guidelines and the Chinese Food Pagoda. The CHDI consists of 13 indexes, including (1) food variety (0-10 points); (2) refined grains (0-5 points); (3)whole grains, dry beans and tubers ( $0-5$ points); (4) total vegetables ( $0-5$ points); (5) dark green and orange vegetables ( $0-5$ points); (6) fruit ( $0-10$ points); ( $)$ dairy ( $0-10$ points); ( 8 ) soybeans ( $0-10$ points); (9) meat and eggs ( $0-5$ points); (10) fish, shellfish and mollusks ( $0-5$ points); ( 11$)$ calories from saturated fatty acids (SoFAAS) (0-10 points); (12) sodium (0-10 points); and (13) calories from empty calories (0-10 points).

The variable, food types reflects the degree of food diversity, and nine food intake indicators are required to evaluate food intake. While calories from SoFAAS reflect the proper selection of high quality protein-source food, empty calories is an indicator for less oil, sugar control and limited alcohol. Scores on each component are summarized and the total score ranges from 0 to 100 ( 0 being the lowest and 100 being the highest possible score). A higher score reflects a better quality of dietary intake. A total score of less than 60 indicates a "poor" quality of dietary intake; a score between 60 and 80 indicates an "average" quality of dietary intake; and a score above 80 indicates "good" dietary intake.

\section{Definitions of Related Indicators}

Calories from SoFAAS was defined as the ratio of saturated fat intake to total energy intake. Empty calories was defined as alcohol, sugar and cooking oil. Sodium intake included the total intake from food, cooking salt and other condiments. Former smokers was defined as that participants who smoked cigarettes in the past, excluding those who took a few tentative puffs. Former drinkers was defined as that participants who drank alcoholic beverages during non-gestational periods in the past, excluding those who sipped some wine.

\section{Statistical Analysis}

All statistical analyses were conducted using EXCEL (2010 Edition, Microsoft, China) software and IBM SPSS Statistics version 21.0 (IBM Corp., Armonk, NY, USA). A p-value $<0.05$ was considered to be statistically significant. Regression coefficients and the $95 \%$ confidence intervals were calculated.

The data on the variables were not normally distributed, and were therefore, summarized as median (interquartile range) and percentage. The Kruskal-Wallis one-way ANOVA (k samples) test was used with the multiple independent samples. All pairwise methods were implemented as pairwise comparisons. Comparisons of proportions were evaluated using the Chi-square test. Univariate and multivariate logistic regression were used in the analyses.

\section{Results}

\section{Characteristics of the Study Participants Stratified by Stage of Pregnancy}

A total of 4574 women were enrolled in the study. Participants were evenly distributed among the three trimesters, with 1661 in early pregnancy (1st trimester), 1549 in middle pregnancy (2nd trimester) and 1364 in late pregnancy (3rd trimester). Among all the participants, $43.6 \%$ lived in urban areas, $26.1 \%$ in suburban areas and $30.4 \%$ in rural areas; $14.4 \%$ were $\geq 35$ years of age. Differences in parity, educational status, family income during the past year and residential area were significant across the three stages of pregnancy $(p<0.05)$ (Table 1). 
Table 1

Characteristics of the study participants stratified by stage of pregnancy.

\begin{tabular}{|c|c|c|c|c|c|c|}
\hline & Early pregnancy & Middle pregnancy & Late pregnancy & Pooled & $x^{2}$ & $p$ \\
\hline $\mathrm{N}$ & 1661 & 1549 & 1364 & 4574 & / & / \\
\hline \multicolumn{7}{|c|}{ Maternal age (years) at delivery $(n, \%)$} \\
\hline$<35$ & $1410(84.9)$ & $1337(91.6)$ & $1174(85.9)$ & $3921(85.7)$ & \multirow[t]{2}{*}{2.36} & \multirow[t]{2}{*}{0.308} \\
\hline$\geq 35$ & $251(15.1)$ & $207(13.4)$ & $184(13.5)$ & $642(14.04)$ & & \\
\hline \multicolumn{7}{|l|}{ Parity (n, \%) } \\
\hline 0 & $1044(37.5)$ & $920(33.1)$ & $819(29.4)$ & $2783(60.8)$ & \multirow[t]{2}{*}{50.60} & \multirow[t]{2}{*}{$<0.001$} \\
\hline$\geq 1$ & $617(34.5)$ & $629(35.1)$ & $545(30.4)$ & $1791(39.2)$ & & \\
\hline \multicolumn{7}{|l|}{ Educational status (n, \%) } \\
\hline$\leq 9$ years & $204(12.3)$ & $277(17.9)$ & $222(16.3)$ & $703(15.4)$ & \multirow[t]{3}{*}{36.53} & \multirow[t]{3}{*}{$<0.001$} \\
\hline Senior high school and college & $647(39.0)$ & $661(42.7)$ & $554(40.6)$ & $1862(40.7)$ & & \\
\hline Bachelor's degree and above & 809 (48.7) & 609 (39.3) & $587(43.0)$ & $2005(43.8)$ & & \\
\hline \multicolumn{7}{|l|}{ Occupational status (n, \%) } \\
\hline Mental & $955(57.5)$ & $863(55.7)$ & $751(55.1)$ & $2569(56.2)$ & \multirow[t]{2}{*}{2.04} & \multirow[t]{2}{*}{0.361} \\
\hline Physical & $699(42.1)$ & $679(43.8)$ & $608(44.6)$ & $1986(43.4)$ & & \\
\hline \multicolumn{7}{|c|}{ Family income for the past year YUAN (n, \%) } \\
\hline$<100000$ & $237(14.3)$ & $287(18.5)$ & $256(18.8)$ & $780(17.1)$ & \multirow[t]{3}{*}{17.95} & \multirow[t]{3}{*}{0.001} \\
\hline $100000-200000$ & $679(40.9)$ & $644(41.6)$ & $554(40.6)$ & $1877(41.0)$ & & \\
\hline$\geq 200000$ & $743(44.7)$ & $613(39.6)$ & $551(40.4)$ & $1907(41.7)$ & & \\
\hline Former smoker (n, \%) & $47(2.8)$ & $41(2.7)$ & $29(2.2)$ & $117(2.6)$ & 1.59 & 0.452 \\
\hline Former drinker (n, \%) & $162(9.8)$ & $177(11.4)$ & $134(9.8)$ & $473(10.3)$ & 2.91 & 0.234 \\
\hline \multicolumn{7}{|l|}{ Ridential area (n, \%) } \\
\hline Urban & $762(45.9)$ & $637(41.1)$ & $593(43.5)$ & $1992(43.6)$ & \multirow[t]{3}{*}{22.65} & \multirow[t]{3}{*}{$<0.001$} \\
\hline Suburban & $459(27.6)$ & $414(26.7)$ & $320(23.5)$ & $1193(26.1)$ & & \\
\hline Rural & $440(26.5)$ & $498(32.1)$ & $451(33.1)$ & $1389(30.4)$ & & \\
\hline
\end{tabular}

\section{Analysis of Daily Dietary Intake of Participants Stratified by Pregnancy Stage and Residential Area}

The median daily intake of the food types are presented in Table 2. Significant differences were found in the median daily intake of cereal, vegetables, livestock and poultry meat, fish and shrimp, eggs, milk and milk products, soybeans and nuts and cooking oil among the women in the different stages of pregnancy $(p<05)$. The median daily intake of cereal, vegetables, livestock and poultry meat, fish and shrimp and cooking oil among participants in late pregnancy was higher than those in middle and early pregnancy. The median daily intake of soybeans and nuts of participants in the middle stage of pregnancy was higher than that of the participants in the early and late stages. Significant differences in the median daily intake of all food types were observed in women from the three residential areas $(p<0.05)$. The median daily intake of cereal, fruits, soybeans and nuts and cooking oil by participants living in rural areas was higher than that of the participants in the suburban and urban areas, whereas the median daily intake of vegetables and livestock and poultry meat by participants in urban areas was higher than that of the women in the suburban and rural areas (Table 2). 
Table 2

Median (M) daily dietary intake of participants stratified by stage of pregnancy and residential area (M, I

\begin{tabular}{|c|c|c|c|c|c|c|c|c|c|c|}
\hline \multirow{2}{*}{$\begin{array}{l}\text { Food types } \\
\text { (g/d) }\end{array}$} & \multirow[t]{2}{*}{ Pooled } & \multicolumn{8}{|c|}{ Pregnancy stage } & \multirow[t]{2}{*}{ F } \\
\hline & & Early & Recommended & Middle & Recommended & Late & Recommended & $\mathbf{F}$ & $p$ & \\
\hline \multirow[t]{2}{*}{ Cereal } & 258.3 & 249.1 & $250-300$ & 262.3 & $275-325$ & 264.3 & $300-350$ & 12.92 & 0.002 & 2 \\
\hline & $(189.6,350.6)$ & $(184.8,338.2)$ & & $(190.8,354.3)$ & & $(193.3,358.8)$ & & & & $(-$ \\
\hline \multirow[t]{2}{*}{ Vegetables } & 158.6 & 154.3 & $300-500$ & 152.9 & $300-500$ & 172.1 & $300-500$ & 14.71 & 0.001 & 1 \\
\hline & $(92.9,267.1)$ & $(89.5,259.4)$ & & $(90.0,260.1)$ & & $(100.0,285.7)$ & & & & ( \\
\hline \multirow[t]{2}{*}{ Fruits } & 221.3 & 224.3 & $200-350$ & 225.9 & $250-350$ & 213.3 & $250-350$ & 2.51 & 0.285 & 2 \\
\hline & $(129.9,360.0)$ & $(130.0,361.6)$ & & $(130.5,364.3)$ & & $(128.6,350.0)$ & & & & ( \\
\hline \multirow{2}{*}{$\begin{array}{l}\text { Livestock } \\
\text { and } \\
\text { poultry } \\
\text { meat }\end{array}$} & 85.3 & 78.5 & $40-65$ & & $50-75$ & & $50-75$ & 55.00 & $<$ & 9 \\
\hline & $(50.0,142.9)$ & $(42.9,129.9)$ & & $(50.2,144.1)$ & & $(59.3,152.4)$ & & & & $(!$ \\
\hline \multirow{2}{*}{$\begin{array}{l}\text { Fish and } \\
\text { shrimp }\end{array}$} & 53.6 & 50.0 & $40-65$ & 51.7 & $50-75$ & 57.1 & $50-75$ & 18.82 & $<$ & 5 \\
\hline & $(28.6,92.9)$ & $(26.4,88.2)$ & & $(28.6,92.9)$ & & $(30.2,101.3)$ & & & & $(\vdots$ \\
\hline \multirow[t]{2}{*}{ Eggs } & 50.0 & 50.0 & 50 & 50.0 & 50 & 50.0 & 50 & 15.69 & & 5 \\
\hline & $(28.6,60.0)$ & $(28.6,57.1)$ & & $(28.6,57.1)$ & & $(30.6,60.0)$ & & & & $(\because$ \\
\hline \multirow{2}{*}{$\begin{array}{l}\text { Milk and } \\
\text { milk } \\
\text { products }\end{array}$} & 200.0 & 200.0 & 300 & 200.0 & $300-500$ & 200.0 & $300-500$ & 38.26 & $<$ & 2 \\
\hline & $(85.7,250.0)$ & $(70.7,250.0)$ & & $(71.4,250.0)$ & & $(100.0,250.0)$ & & & & $(\xi$ \\
\hline \multirow{2}{*}{$\begin{array}{l}\text { Soybeans } \\
\text { and nuts }\end{array}$} & 31.6 & 29.80 & 25 & 34.10 & 30 & 31.3 & 30 & 11.46 & 0.003 & 3 \\
\hline & $(15.2,59.4)$ & $(14.15,57.10)$ & & $(16.20,63.70)$ & & $(15.9,58.8)$ & & & & ( \\
\hline \multirow[t]{2}{*}{ Salt } & 5.5 & 5.4 & $<6$ & 5.5 & $<6$ & 5.5 & $<6$ & 1.00 & 0.608 & 5 \\
\hline & $(3.4,7.8)$ & $(3.3,7.9)$ & & $(3.4,7.8)$ & & $(3.4,7.7)$ & & & & $(\vdots$ \\
\hline \multirow{2}{*}{$\begin{array}{l}\text { Cooking } \\
\text { oil }\end{array}$} & 22.1 & 21.1 & $25-30$ & 22.3 & $25-30$ & 23.1 & $25-30$ & 8.92 & 0.012 & 2 \\
\hline & $(11.9,33.9)$ & $(11.3,32.1)$ & & $(12.0,34.8)$ & & $(12.4,35.5)$ & & & & ( \\
\hline
\end{tabular}

\section{Analysis of CHDI Scores of Participants Stratified by Pregnancy Stage and Residential Area}

The median score for each component of the CHDI and the total median CHDI score is presented in Table 3. The total scores of the participants in the early, middle and late stages of pregnancy were 71.5, 71.1 and 71.2., respectively. Significant differences in median scores were found for the CHDI components, including food variety, total vegetables, dark green and orange vegetables, fruit, diary, soybeans, meat and eggs, calories from saturated fatty acids, sodium and empty calories and the total scores of the women across the three trimesters $(p<0.05)$. The median CHDI scores for total vegetables, diary, fish, shellfish and mollusks and sodium among participants in late pregnancy were higher than those of the women in the early and middle stages. The scores of participants in early pregnancy for dark green and orange vegetables and calories from saturated fatty acids were higher than those of participants in middle and late pregnancy. 
Table 3

Distribution of the China Healthy Diet Index (CHDI) scores by residential area and pregnancy stage (M, P25, P75).

\begin{tabular}{|c|c|c|c|c|c|c|c|c|c|c|c|c|}
\hline \multirow{2}{*}{$\begin{array}{l}\text { CHDI } \\
\text { components }\end{array}$} & \multirow{2}{*}{$\begin{array}{l}\text { Score } \\
\text { range }\end{array}$} & \multirow[t]{2}{*}{ Pooled } & \multicolumn{5}{|c|}{ Pregnancy stage } & \multicolumn{5}{|c|}{ Residential area } \\
\hline & & & Early & Middle & Late & $\mathbf{F}$ & $p$ & Urban & Suburban & Rural & $F$ & $p$ \\
\hline \multirow[t]{2}{*}{ Food variety } & \multirow[t]{2}{*}{$0-10$} & 10.0 & 10.0 & 10.0 & 10.0 & \multirow[t]{2}{*}{27.74} & \multirow{2}{*}{$<.001$} & 10.0 & 10.0 & 10.0 & \multirow[t]{2}{*}{60.7} & \multirow{2}{*}{$\begin{array}{l}<.001 \\
0.00\end{array}$} \\
\hline & & $(7.9,10.0)$ & $(7.5,10.0)$ & $(8.2,10.0)$ & $(8.3,10.0)$ & & & $(7.8,10.0)$ & $(7.3,10.0)$ & $(8.9,10.0)$ & & \\
\hline \multirow{2}{*}{$\begin{array}{l}\text { Refined } \\
\text { grains }\end{array}$} & \multirow[t]{2}{*}{$0-5$} & 5.0 & 5.0 & 5.0 & 5.0 & \multirow[t]{2}{*}{2.84} & \multirow[t]{2}{*}{0.242} & 5.0 & 5.0 & 5.0 & \multirow[t]{2}{*}{21.8} & \multirow{2}{*}{$\begin{array}{l}<.001 \\
0.001\end{array}$} \\
\hline & & $(4.8,5.0)$ & $(4.8,5.0)$ & $(4.7,5.0)$ & $(4.8,5.0)$ & & & $(4.5,5.0)$ & $(5.0,5.0)$ & $(4.8,5.0)$ & & \\
\hline \multirow{2}{*}{$\begin{array}{l}\text { Whole } \\
\text { grains, dry } \\
\text { beans and } \\
\text { tubers }\end{array}$} & \multirow[t]{2}{*}{$0-5$} & 1.0 & 1.0 & 1.0 & 0.9 & \multirow[t]{2}{*}{0.59} & \multirow[t]{2}{*}{0.743} & 1.0 & 1.0 & 0.9 & \multirow[t]{2}{*}{4.1} & \multirow[t]{2}{*}{0.129} \\
\hline & & $(0.4,1.8)$ & $(0.4,1.8)$ & $(0.5,1.8)$ & $(0.4,1.8)$ & & & $(0.5,1.8)$ & $(0.5,1.8)$ & $(0.4,1.8)$ & & \\
\hline \multirow{2}{*}{$\begin{array}{l}\text { Total } \\
\text { vegetables }\end{array}$} & \multirow[t]{2}{*}{$0-5$} & 2.4 & 2.4 & 2.3 & 2.5 & \multirow[t]{2}{*}{13.25} & \multirow[t]{2}{*}{0.001} & 2.6 & 2.4 & 2.3 & \multirow[t]{2}{*}{36.2} & \\
\hline & & $(1.6,3.8)$ & $(1.6,3.8)$ & $(1.5,3.6)$ & $(1.7,4.0)$ & & & $(1.7,4.1)$ & $(1.5,3.6)$ & $(1.5,3.6)$ & & \\
\hline Dark green & $0-5$ & 2.0 & 2.1 & 1.9 & 2.1 & 11.46 & 0.003 & 2.2 & 1.9 & 1.8 & 34.3 & \\
\hline vegetables & & $(1.3,3.3)$ & $(1.3,3.3)$ & $(1.2,3.1)$ & $(1.3,3.5)$ & & & $(1.4,3.6)$ & $(1.2,3.2)$ & $(1.2,3.1)$ & & \\
\hline Fruits & $0-10$ & 10.0 & 10.0 & 10.0 & 9.5 & 12.84 & 0.002 & 9.7 & 10.0 & 9.7 & 21.0 & \\
\hline & & $(6.1,10.0)$ & $(6.3,10.0)$ & $(6.1,10.0)$ & $(5.9,10.0)$ & & & $(6.1,10.0)$ & $(6.7,10.0)$ & $(5.9,10.0)$ & & \\
\hline Diary & $0-10$ & 8.2 & 8.0 & 8.0 & 8.7 & 13.43 & 0.001 & 8.6 & 8.2 & 7.8 & 6.8 & 0.034 \\
\hline & & $(4.0,10.0)$ & $(3.8,10.0)$ & $(3.6,10.0)$ & $(4.5,10.0)$ & & & $(4.0,10.0)$ & $(4.3,10.0)$ & $(3.6,10.0)$ & & \\
\hline Soybeans & $0-10$ & 10.0 & 10.0 & 10.0 & 10.0 & 11.70 & 0.003 & 10.0 & 10.0 & 10.0 & 17.2 & \\
\hline & & $(6.1,10.0)$ & $(5.7,10.0)$ & $(6.4,10.0)$ & $(6.6,10.0)$ & & & $(6.8,10.0)$ & $(5.7,10.0)$ & $(5.6,10.0)$ & & \\
\hline Meat and & $0-5$ & 5.0 & 5.0 & 5.0 & 5.0 & 28.68 & & 5.0 & 5.0 & 5.0 & 77.6 & $<$ \\
\hline & & $(5.0,5.0)$ & $(4.8,5.0)$ & $(4.9,5.0)$ & $(5.0,5.0)$ & & & $(5.0,5.0)$ & $(4.7,5.0)$ & $(4.5,5.0)$ & & \\
\hline $\begin{array}{l}\text { Fish, } \\
\text { shellfish }\end{array}$ & $0-5$ & 4.7 & 4.7 & 4.5 & 4.9 & 4.38 & 0.112 & 5.0 & 4.0 & 4.7 & 67.2 & $<001$ \\
\hline $\begin{array}{l}\text { and } \\
\text { mollusks }\end{array}$ & & $(2.5,5.0)$ & $(2.4,5.0)$ & $(2.4,5.0)$ & $(2.6,5.0)$ & & & $(3.0,5.0)$ & $(2.1,5.0)$ & $(2.2,5.0)$ & & \\
\hline Calories & $0-10$ & 2.2 & 2.7 & 1.8 & 2.0 & 6.63 & 0.036 & 2.2 & 1.6 & 2.7 & 9.7 & 0.008 \\
\hline $\begin{array}{l}\text { saturated } \\
\text { fatty acids }\end{array}$ & & $(0.0,6.9)$ & $(0.0,7.3)$ & $(0.0,6.9)$ & $(0.0,6.5)$ & & & $(0.0,6.7)$ & $(0.0,6.5)$ & $(0.0,7.7)$ & & \\
\hline Sodium & $0-10$ & 7.2 & 7.1 & 7.1 & 7.3 & 8.44 & 0.015 & 7.1 & 6.8 & 7.5 & 45.8 & $<$ \\
\hline & & $(4.8,8.9)$ & $(4.7,8.8)$ & $(4.7,9.0)$ & $(5.1,9.0)$ & & & $(4.8,8.8)$ & $(4.3,8.7)$ & $(5.3,9.3)$ & & \\
\hline $\begin{array}{l}\text { Empty } \\
\text { calories }\end{array}$ & $0-10$ & 10.0 & 10.0 & 10.0 & 10.0 & 11.47 & 0.003 & 10.0 & 10.0 & 10.0 & 32.6 & $<001$ \\
\hline & & $(10.0,10.0)$ & $(10.0,10.0)$ & $(10.0,10.0)$ & $(10.0,10.0)$ & & & $(10.0,10.0)$ & $(10.0,10.0)$ & $(10.0,10.0)$ & & \\
\hline Total score & 100 & 71.5 & 71.1 & 71.2 & 72.3 & 16.65 & $<$ & 72.4 & 70.4 & 71.2 & 30.1 & $<001$ \\
\hline & & $(63.9,77.9)$ & $(63.7,77.5)$ & $(63.3,77.5)$ & $(65.1,78.7)$ & & & $(64.6,78.6)$ & $(63.3,76.3)$ & $(63.4,78.2)$ & & \\
\hline
\end{tabular}

The total scores of participants living in urban, suburban and rural areas were 72.4, 70.4 and 71.2, respectively. Significant differences were found in the median $\mathrm{CHDI}$ scores on all components except whole grains and dry beans and tubers among the participants in the three residential areas. The median $\mathrm{CHDI}$ scores for total vegetables, dark green and orange vegetables, dairy and fish, shellfish and mollusks were higher in the participants in urban areas than those of participants in suburban and rural areas. The CHDI scores for calories from saturated fatty acids and sodium were higher among the participants in rural areas than those of participants in urban and suburban areas (Table 3).

The analysis of the composition ratio of $\mathrm{CHDI}$ showed that $13.7 \%$ of participants had scores below 60 points. Significant differences in the $\mathrm{CHDI}$ score compositions of the participants in the different trimesters and residential areas were found $(\mathrm{X} 2=14.95,33.75 ; p=0.005,<0.001)$. The proportion of scores $<$ 60 among women in the late stage of pregnancy was lower than that of the women in the early and middle stages. The proportion of participants with a score $<60$ was higher among those in suburban and rural areas compared to those in urban areas (Fig. 1).

\section{Multivariate Analysis of CHDI Scores}

CHDI scores were categorized as $<60$ and $\geq 60$ for the analyses. Univariate and multivariate logistic regression analyses were conducted; scores $<60$ points were set as " 0 " and scores $\geq 60$ as " 1 ." General characteristics, pregnancy stage and residential area were treated as independent variables and CHDI score as the dependent variable. 
The univariate logistic regression showed that residential area, stage of pregnancy, educational background and family income were significantly correlated with $\mathrm{CHDI}$ score $(p<0.05)$. The multivariate logistic regression showed a significant difference in CHDI scores among participants in the different trimesters. Participants in early and middle pregnancy had lower scores, compared to those in late pregnancy $(p<0.05)$. Participants living in urban areas tended to have higher CHDI scores, compared to those in suburban and rural areas. Women with less than nine years of formal education had lower scores compared to those with more education (i.e., senior high school and college) and above, and a family income less than 100000 Yuan during the past year was associated with lower scores compared to the two higher levels of family income (Table 4). 
Table 4

Logistic regression models for the China Healthy Diet Index (CHDI).

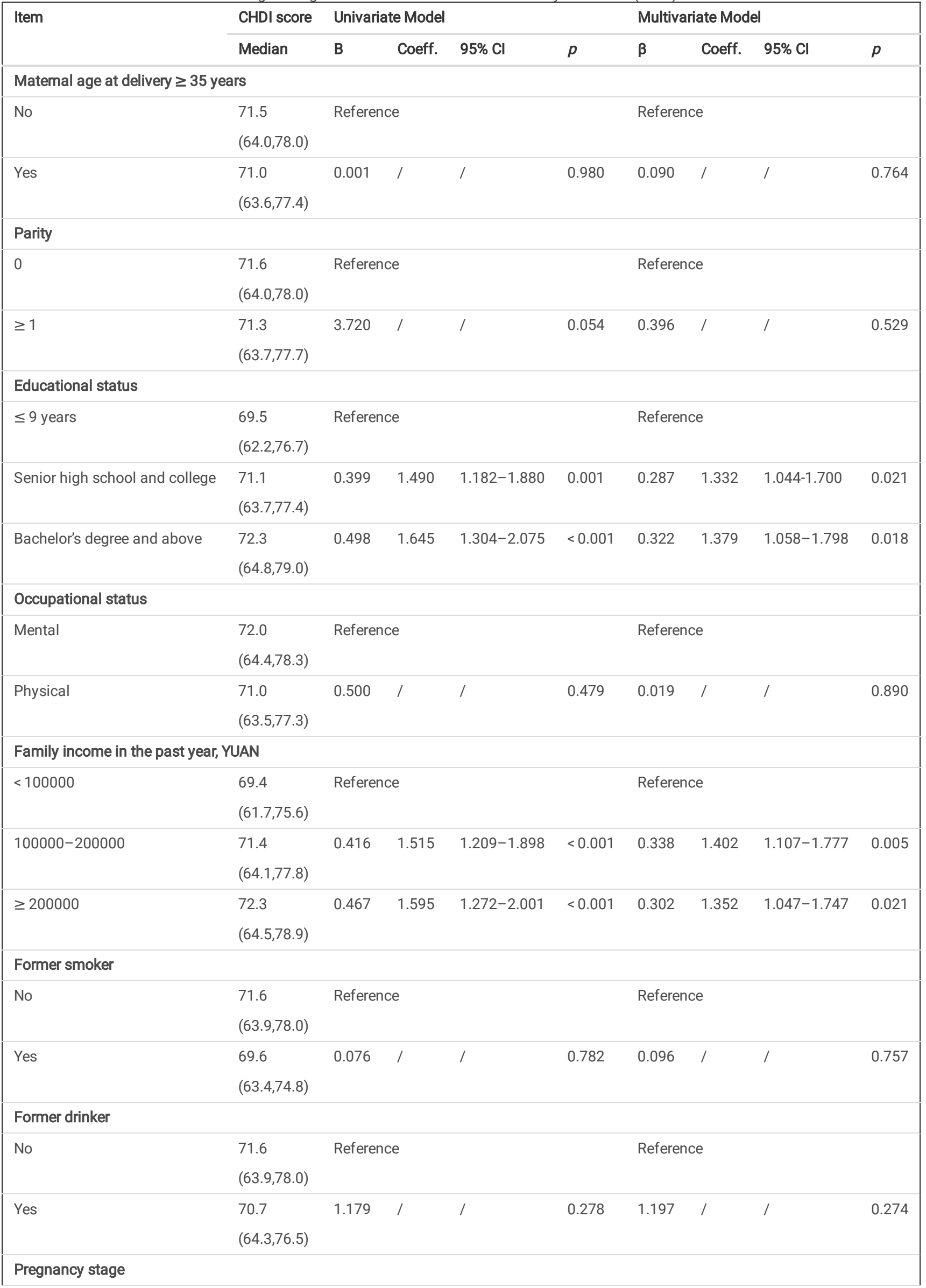




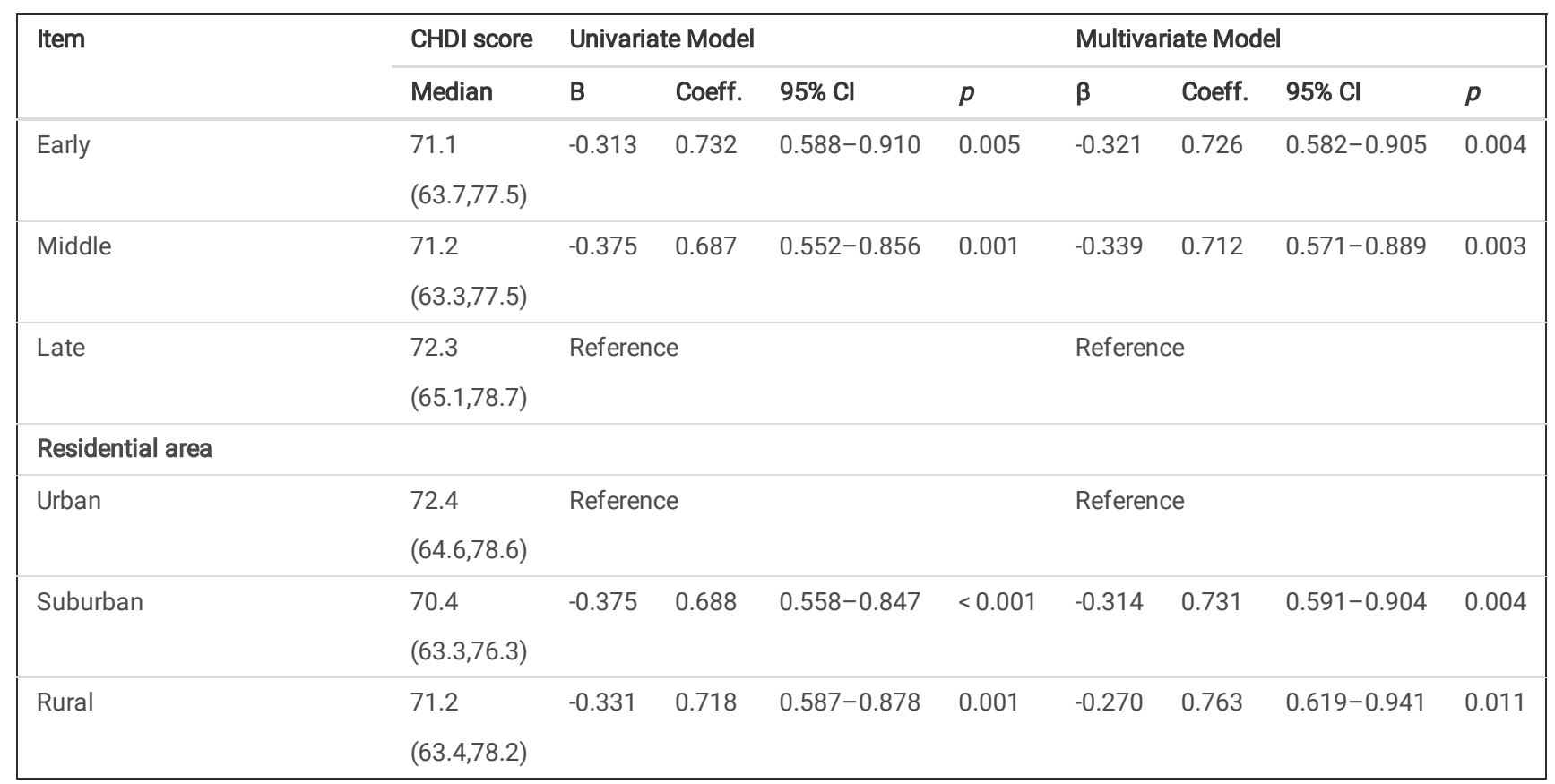

\section{Discussion}

Nutrition is a predictor of pregnancy success and dietary patterns can affect pregnant women for the rest of their lives. The overall diet quality of pregnant women in Shanghai was found in this study to be average, and unbalanced, which is similar to the previous findings of Shanghai residents [13]. The median CHDI score was 71.5 and merely $18.4 \%$ scored $\geq 80$ points, which is higher than that of a national sample 7 and Shanghai senior high school students [14]. Pregnancy stages and residential areas were associated with CHDI scores, as were socioeconomic factors (educational level and family income). The dietary scores of urban residents were higher than those of suburban and rural residents, and being in the later stages of pregnancy served as a protective factor for good dietary intake.

Pregnant women in Shanghai ate a wide variety of foods with an over-intake of meat and under-intake of whole grains, dairy products and vegetables. The under-consumption of whole grains, dry beans and tubers may be related to the diet habits of Shanghai residents, which is difficult to change in a short time. Whole grains and its constituents have antioxidants and anti-inflammatory properties, which promote fertility [15]; a fertility clinic study showed that a higher intake of whole grains was associated with better birth outcomes [16]. Although the promotion of whole grain consumption has been on-going since the establishment of the Chinese Dietary Guidelines in 2016 [17], people in the southern region of China are accustomed to living on rice on a long-term basis, which leads to the insufficient consumption of whole grains, such as corn, millet, buckwheat and miscellaneous beans. The median dairy intake of the participants in this study was merely $200 \mathrm{~g} / \mathrm{d}$, which was far from the recommended intake for pregnant women (300-500 g/d). Milk products are excellent sources of calcium and protein for maternal and fetal health rather than other foods, and a chronic calcium deficiency may cause increased bone loss during pregnancy $[18,19]$. Lactose intolerance is common in China as lactase deficiency affects $80 \%-90 \%$ of women three to four years after weaning, and $66.5 \%$ of adults have symptoms of lactose intolerance [20]. Fermented dairy products, such as cheese and yogurt, are alternatives that are more suitable for individuals with lactose intolerance. Another diet problem lies in the severely inadequate consumption of total vegetables, dark green and orange vegetables and overconsumption of meat, which was also reported in a previous national survey in 2010-2012 [21]. The median total intake of vegetables and livestock and poultry meat of the participants in this study was $158.6 \mathrm{~g} / \mathrm{d}$ and $85.3 \mathrm{~g} / \mathrm{d}$, respectively. Interestingly, pregnant women were advised to have $300-500 \mathrm{~g} / \mathrm{d}$ of total vegetables and $40-75 \mathrm{~g} / \mathrm{d}$ of livestock and poultry meat and dark green and orange vegetables, which would account for over $66.7 \%$ of all the vegetables consumed [17]. Several studies have proposed that a healthy diet comprised of sufficient vegetables is associated with a reduction in the risk of gestational diabetes mellitus during pregnancy while a higher consumption of total meat, especially red and processed meat, could increase the hazard [22, 23].

We found that participants in later pregnancy had a relatively higher overall diet quality compared to those in early pregnancy, which may be related to the stress of pregnancy. A cohort study from the FUDAN School of Public Health, which included 2634 participants, found that increased pregnancy-specific stress in the middle and third trimesters may motivate pregnant women to follow a healthy balanced diet, and thus, equip them with more nutritional knowledge compared to novices in their first trimester, which was thought as the weak association with poor birth outcomes in previous studies [24, 25]. Compared to the chronic stress experienced during early pregnancy, the stress in the later trimesters is acute stress, characterized by increased blood sugar and poor appetite, which lure pregnant women to choose food that stimulates their appetite to meet their nutritional needs prior to labor [26, 27]. Hence, it is important to strengthen diet-related health education for pregnant women during all trimesters, especially the first one.

Residential area was found to be another determining factor of dietary quality. The dietary scores of the urban residents were higher than those of the suburban and rural residents. People dwelling in the countryside tend to consume more refined grain and less vegetables and meat, which is consistent with the finding Dibsdall LA [28] and associated with the local food environment and food availability. Full-service supermarkets and grocery stores in downtown are more densely distributed than those in the remote areas are. Another explanation may be related to differences in socioeconomic status among the urban, suburban and rural areas. A large amount of epidemiologic data has revealed an association of diet quality with the socioeconomic status [29]. Educational and family income levels were also found to be protective factors in our study, the distribution of which differed between the residential areas. Pregnant 
women with high educational levels have more opportunities to earn more money and settle downtown rather than in rural areas. They are likely to have higher rates of literacy and healthier dietary habits [30]. Their work experience might empower them to make better decisions about their dietary healthcare during pregnancy [31], and thus, have a higher diet quality. Pregnant women with lower incomes tend to consume fewer fruits and vegetables and more sugarsweetened beverages [32], as the cost of food is an insurmountable gap for them, making it a challenge to access nutrient-dense diets [29].

To the best of our knowledge, this is the first study to apply CHDI indicators to assess diet quality among pregnant woman in coastal areas across trimesters and residential areas. This investigation was a systematic sampling survey covering all districts of Shanghai using a large representative sample and reasonable survey methods, which reflects the dietary intake of the population and should lead to generalizable conclusions. However, our study has limitations. The CHDI has some drawbacks. Each CHDI score has only a single threshold and it cannot explain the balance of the overall dietary pattern of a target population. Too much or too little consumption of one food type is not fully reflected in the total score; furthermore, this imbalance also affects the scores on the other items. Thus, the CHDI score needs to be evaluated and combined with a quantitative assessment of dietary intake. Health outcomes were not assessed in this study, and thus, the relationship between the $\mathrm{CHDI}$ and health outcomes should be evaluated in the future.

\section{Conclusion}

Pregnant women living in coastal areas of China suffer from an unbalanced diet of average quality, with $13.7 \%$ of participants in this study scoring below 60 points, indicating "poor" diet quality. Pregnancy stage and residential area were associated with diet quality. Pregnant women in the early and middle stages of pregnancy had worse scores than those in the late stage, while suburban and rural women had worse scores than urban women. Relevant health education should be strengthened to guide pregnant women in making reasonable food choices, especially those living in suburban and rural areas and those in their first and second trimesters.

\section{Declarations}

\section{Acknowledgements}

We are grateful to all the participants in the study, and the healthcare professionals from the Centers for Disease Control and Prevention of Shanghai.

\section{Authors' contributions}

Z.W., J.Z., C.W. and C.G. designed research; Z.W. and J.S. analyzed data; Z.W., J.S. and Y.W. wrote the paper; X.C, Q.S., Z.S. and W.J. conducted research; All authors have read and approved the final manuscript.

\section{Funding}

The current study was supported by the young fund of Shanghai municipal health commission (20194Y0443), food nutrition research and education fund of Danone nutrition center (DIC2019-03), excellent young talents of health system in Shanghai (No. 2017YQ043) and top young talents in Shanghai (No. 2020-8).

\section{Availability of data and materials}

The datasets generated and analyzed during the current study are not publicly available but are available from the corresponding author on reasonable request.

\section{Ethics approval and consent to participate}

This study was conducted according to the guidelines laid down in the Declaration of Helsinki and all procedures involving human subjects were approved by the Shanghai Municipal Centre for Disease Control and Prevention. Written informed consent was obtained from all participants.

\section{Consent for publication}

Not applicable.

\section{Conflict of Interest}

All authors declare that we have no known competing financial interests or personal relationships that could have appeared to influence the work reported in this paper.

\section{Author details}

${ }^{1}$ Division of Health Risk Factors Monitoring and Control, Shanghai Municipal Center for Disease Control and Prevention, Shanghai 200336, China; ${ }^{2}$ General Office, Shanghai Municipal Center for Disease Control and Prevention, Shanghai 200336, China.

\section{References}

1. Langley-Evans SC. Nutrition in early life and the programming of adult disease: a review. J Hum Nutr Diet. 2015;28(Suppl 1):1-14.

2. Procter SB, Campbell CG. Position of the Academy of Nutrition and Dietetics: nutrition and lifestyle for a healthy pregnancy outcome. J Acad Nutr Diet. 2014;114(7):1099-103. 
3. Dubois L, Diasparra M, Bedard B, et al.(2017) Adequacy of nutritional intake from food and supplements in a cohort of pregnant women in Quebec, Canada: the 3D Cohort Study (Design, Develop, Discover). Am J Clin Nutr, 2017, 106(2):541-548.

4. Borge TC, Aase H, Brantsaeter AL, Biele G. The importance of maternal diet quality during pregnancy on cognitive and behavioural outcomes in children: a systematic review and meta-analysis. BMJ Open. 2017;7(9):e16777.

5. Haines PS, Siega-Riz AM, Popkin BM. The Diet Quality Index revised: a measurement instrument for populations. J Am Diet Assoc. 1999;99(6):697-704.

6. Altavilla C, Caballero-Pérez P. An update of the KIDMED questionnaire, a Mediterranean Diet Quality Index in children and adolescents. Public Health Nutr. 2019;22(14):2543-7.

7. Yu-na H, Yue-hui F, Xiao-guang Y, Gang-qiang D. Establishment and Application of China Healthy diet index. ACTA Nutrimenta SINICA. 2017;39:436-41.

8. Wu W, Zhao A, Szeto IM, et al. Diet quality, consumption of seafood and eggs are associated with sleep quality among Chinese urban adults: A crosssectional study in eight cities of China. Food Sci Nutr. 2019;7(6):2091-102.

9. Chan R, Chan D, Woo J. A cross sectional study to examine the association between dietary patterns and cognitive impairment in older Chinese people in Hong Kong. J Nutr Health Aging. 2013;17(9):757-65.

10. Hamner HC, Moore LV. Dietary quality among children from 6 months to 4 years, NHANES 2011-2016. Am J Clin Nutr. 2020;111(1):61-9.

11. Jun S, Jiajie Z, Hongmei T, et al. Relative validity of food frequency questionnaire for estimating dietary nutrients intake. Wei Sheng Yan Jiu. 2016;45(5):743-8.

12. Yang Y. China food composition. Peking: Peking University Medical Press; 2009.

13. Zang J, Yu H, Zhu Z, et al. Does the Dietary Pattern of Shanghai Residents Change across Seasons and Area of Residence: Assessing Dietary Quality Using the Chinese Diet Balance Index (DBI). NUTRIENTS. 2017;9(3):251.

14. Zhengyuan W, Jiachang C, Zhenni Z, et al. Evaluation of dietary intake quantity and quality of high school students in Shanghai City. Wei Sheng Yan Jiu. 2019;48(4):560-6.

15. Chiu YH, Chavarro JE, Souter I. Diet and female fertility: doctor, what should I eat? Fertil Steril. 2018;110(4):560-9.

16. Gaskins AJ, Chiu YH, Williams PL, et al. Maternal whole grain intake and outcomes of in vitro fertilization. Fertil Steril. 2016;105(6):1503-10.

17. Chinese Nutrition Society. Chinese dietary guidelines. Beijing: People's Medical Publishing House; 2016.

18. Hacker AN, Fung EB, King JC. Role of calcium during pregnancy: maternal and fetal needs. Nutr Rev. 2012;70(7):397-409.

19. Hofmeyr GJ, Manyame S. Calcium supplementation commencing before or early in pregnancy, or food fortification with calcium, for preventing hypertensive disorders of pregnancy. Cochrane Database Syst Rev. 2017;9(9):CD011192.

20. Lomer MC, Parkes GC, Sanderson JD. Review article: lactose intolerance in clinical practice-myths and realities. Aliment Pharmacol Ther. 2008;27(2):93103.

21. Cui-hua H, Ye L, Jia-jie Z, et al. Nutrition transition among residents in shanghai: Data Analysis based on national nutrition and health surveys in 19822012. Journal of Environmental Occupational Medicine. 2016;33(19):845-8.

22. Mari-Sanchis A, Diaz-Jurado G, Basterra-Gortari FJ, et al. Association between pre-pregnancy consumption of meat, iron intake, and the risk of gestational diabetes: the SUN project. Eur J Nutr. 2018;57(3):939-49.

23. Vezina-Im LA, Godin G, Couillard C, et al. Validity and reliability of a brief self-reported questionnaire assessing fruit and vegetable consumption among pregnant women. BMC PUBLIC HEALTH. 2016;16:982.

24. Heidari Z, Jalali S, Sedaghat F, et al. Dietary patterns and breast cancer risk among Iranian women: A case-control study. Eur J Obstet Gynecol Reprod Biol. 2018;230:73-8.

25. Freitas-Vilela AA, Pearson RM, et al. Maternal dietary patterns during pregnancy and intelligence quotients in the offspring at 8 years of age: Findings from the ALSPAC cohort. Matern Child Nutr. 2018;14(1):e12431.

26. Lopez RB, Courtney AL, Wagner DD. Recruitment of cognitive control regions during effortful self-control is associated with altered brain activity in control and reward systems in dieters during subsequent exposure to food commercials. Peer J. 2019;7:e6550.

27. Rabasa C, Askevik K, Schele E, et al. Divergent Metabolic Effects of Acute Versus Chronic Repeated Forced Swim Stress in the Rat. Obesity (Silver Spring). 2019;27(3):427-33.

28. Dibsdall LA, Lambert N, Bobbin RF, et al. Low-income consumers' attitudes and behaviour towards access, availability and motivation to eat fruit and vegetables. Public Health Nutr. 2003;6(2):159-68.

29. Darmon N, Drewnowski A. Does social class predict diet quality? Am J Clin Nutr. 2008;87(5):1107-17.

30. Kastro S, Demissie T, Yohannes B. Low birth weight among term newborns in Wolaita Sodo town, South Ethiopia: a facility based cross-sectional study. BMC Pregnancy Childbirth. 2018;18(1):160.

31. Redman K, Ruffman T, Fitzgerald P, et al. lodine Deficiency and the Brain: Effects and Mechanisms. Crit Rev Food Sci Nutr. 2016;56(16):2695-713.

32. French SA, Tangney CC, Crane MM, et al. Nutrition quality of food purchases varies by household income: the SHoPPER study. BMC Public Health. 2019;19(1):231.

\section{Figures}




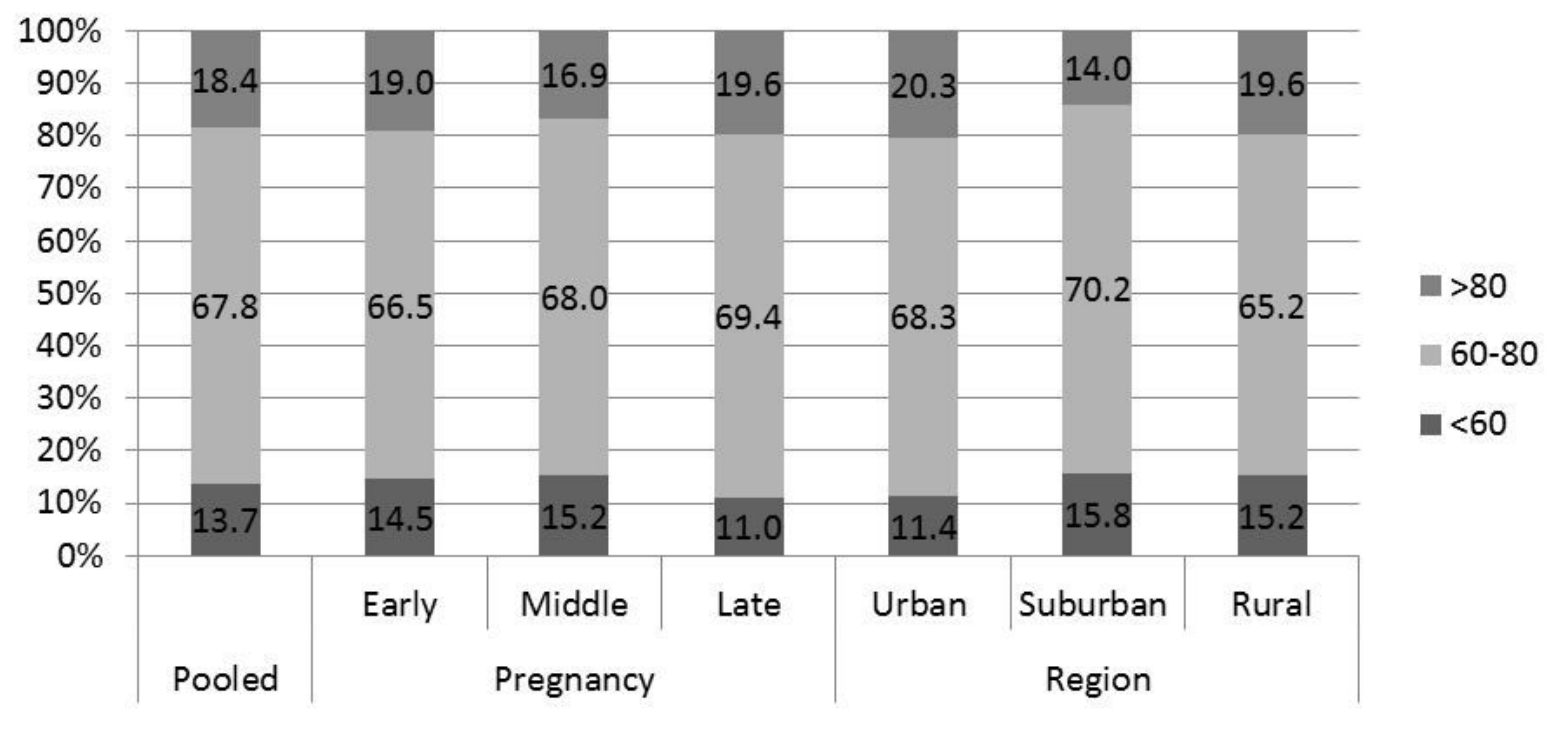

Figure 1

The China Healthy Diet Index (CHDI) composition ratios for the different residential areas and pregnancy stages. 